\title{
МОДИФИЦИРОВАННАЯ МОДЕЛЬ СОЛОУ-СВАНА ЭКОНОМИКИ РОССИИ
}

\author{
(C) 2019 Митрофанов Алексей Юрьевич \\ доцент кафедры Статистики \\ Саратовский социально-экономический институт (филиал) РЭУ имени Г.В. Плеханова, Россия, Саратов \\ E-mail: MitrofanovAY0@gmail.com
}

В статье рассматривается построение макроэкономической модели роста экономики России, представляющей собой модификацию классической модели Солоу-Свана. Ключевой особенностью модели (с дискретным временем) является взаимосвязь между услугами капитала и темпом его прироста. Динамика труда описывается моделью Бевертона-Холта. Использованы данные мировой таблицы Пенн, версия 9.1. На основе модели построен прогноз развития экономики России до 2025 г.

Ключевые слова: макроэкономика, модель Солоу-Свана, модель роста, Российская Федерация, мировая таблица Пенн, капитал, услуги капитала, модель Бевертона-Холта, эконометрика, прогноз

\section{Введение}

Замедление роста экономики Российской Федерации, произошедшее в недавнем прошлом, и, несомненно, связанное с ним снижение реальных доходов населения, обуславливает повышенный интерес к вопросам роста экономики и факторам, его обуславливающим (уточним, что в данной работе мы не рассматриваем вопросы устойчивости роста).

Значительный интерес вызывают, в частности, вопросы о влиянии на рост экономики России западных санкций и контрсанкций, недавних решений Правительства РФ о повышении пенсионного возраста и ставки НДС и связанные вопросы о перспективах экономического роста российской экономики в среднесрочной перспективе. Отметим, что текущая (поквартальная) экономическая информация Росстата, многократно обновляемые на протяжении года прогнозы экономического роста Минэкономразвития и зарубежных аналитиков (в частности, Всемирного банка), не дают ответа на эти ключевые вопросы и, в известной степени, отвлекают от них, поскольку для «представительного» жителя страны и предпринимателя имеют существенное значения лишь данные за год и за несколько лет.

В данной работе даём частичные ответы на эти вопросы, основываясь на модификации экономической модели Солоу-Свана и данных из источника высочайшего качества статистических данных об экономическом росте большинства стран мира - мировой таблицы Пенн (Penn World Table) до 2017 г. включительно [13].

Целями работы являются: 1) построение макроэкономической модели роста экономики России, представляющей собой модификацию классической модели Солоу-Свана; 2) построение с помощью модели прогноза развития экономики России до 2025 г.

Ключевые особенности модели: 1) время дискретно; 2) разработана взаимосвязь между услугами капитала и темпом его прироста; 3) для описания динамики труда используется модель Бевертона-Холта; 4) в качестве исходных данных использована мировая таблица Пенн (Penn World Table), версия 9.1.

Неоклассическая модель роста Солоу-Свана

Неоклассическая модель роста Солоу-Свана стандартная модель для теоретического анализа роста национальной экономики, независимо разработанная Робертом Солоу и Тревором Сваном и опубликованная в 1956 г. [7, с. 26].

Существуют варианты модели Солоу-Свана с непрерывным и дискретным временем (мы используем дискретное время). Обобщённый вариант модели [7, с. 26] основывается на следующих предположениях: 1) экономика производит одно потребительское и инвестиционное благо, объём выпуска которого в год $\mathrm{t}$ обозначается $\mathrm{Y}_{\mathrm{t}}$; 2) валовой выпуск экономики (ВВП) определятся по запасу капитала $\mathrm{K}_{\mathrm{t}}$ (capital stock), объёму труда $L_{t}$ и технологическому прогрессу $A_{t}$ : $\mathrm{Y}_{\mathrm{t}}=\mathrm{F}\left(\mathrm{K}_{\mathrm{t}}, \mathrm{L}_{\mathrm{t}}, \mathrm{A}_{\mathrm{t}}\right)$, где $\mathrm{F}(\mathrm{K}, \mathrm{L}, \mathrm{A})-$ производственная функция, линейно-однородная по $\mathrm{K}$ и $\mathrm{L}$, удовлетворяющая ряду ограничений на частные производные и так называемым условиям Инада; 3) динамика капитала задаётся уравнением: $\mathrm{K}_{\mathrm{t}+1}=\mathrm{sY}_{\mathrm{t}}+(1-\delta) \mathrm{K}_{\mathrm{t}}$, где $\mathrm{s}-$ норма инвестирования, предполагающаяся постоянной, $\delta-$ норма 
амортизации капитала; 4) объем труда задаётся как показательная функция времени: $\mathrm{L}_{\mathrm{t}}=\mathrm{L}_{0} \mathrm{r}^{\mathrm{t}}$

Основным преимуществом модели СолоуСвана является простота её теоретического анализа (особенно удобен вариант с непрерывным временем), позволяющего сделать много содержательных заключений о росте национальной экономики. Содержательность модели обуславливает желание оценить её на реальных данных, однако на этом пути исследователь сталкивается с рядом трудностей: 1) неоднородность выпуска экономики и наличие множества инвестиционных активов; 2) непостоянство и эндогенность нормы инвестирования; 3) отклонение динамики от экспоненциального закона и его эндогенность; 4) отсутствие линейной однородности производственной функции. Рассмотрим их более подробно.

Имеется стандартный метод, позволяющий охарактеризовать валовой выпуск многопродуктовой экономики - использовать валовой внутренний продукт; в качестве $\mathrm{Y}_{\mathrm{t}}$ мы используем реальный ВВП.

Неоднородность капитала является более серьёзным препятствием. В модели Солоу-Свана неявно предполагается, что капитал однороден по своему составу. В реальности это не так - различные виды капитала характеризуются различными уровнями предельной производительности. Как отмечается в [9], использование оценок капитала, основанное лишь на данных национальных счетов, приводит к недооценке роли капитала. Там же отмечается, то страны с высоким уровнем экономического развития, как правило, вкладывают больше средств в краткосрочные активы, такие как компьютеры и программное обеспечение, и меньше в «долгоживущие» активы, такие как офисные здания или дороги. В упомянутой работе рассматривается методика оценивания услуг капитала, основанная на издержках на приобретения/аренды элементов капитала, хотя, как отмечают авторы, эта работа не является пионерской в данном направлении. Применяя эконометрические методы, авторы подтверждают, что страны с высоким среднедушевым доходом больше инвестируют в активы с небольшим временем жизни.

Подход, основанный на потоке услуга капитала, также упоминается в [3] как средство повышения точности производственной функции. Трудности, связанные с оценкой запаса капитала, отмечаются в [2], [4] и возникают при попыт- ках вычисления так называемого остатка Солоу - по сути, ряда остатков производственной функции, в том числе для экономики региона [5].

Остаток Солоу, также называемый совокупной факторной производительностью (СФП), и первая методика его вычисления были предложены в работе Р. Солоу 1957 г. Минэкономразвития России выделяет факторы развития страны, т.е. использует макроэкономическую производственную функцию; также увеличение СФП рекомендуется А. Кудриным в качестве одного из наиболее действенных факторов увеличения ВВП [6].

Имеются макроэкономические модели роста, описывающие норму инвестирования как непостоянную (эндогенную). При этом привлекается микроэкономическая теория принятия инвестиционных решений фирм и домохозяйств, см. [7, гл. 5]. В [1] производится математический анализ чувствительности одной из таких моделей, а также приводятся результаты (частичного) оценивания модели по данным трёх стран ЕС, при этом норма амортизации капитала выбираются экспертно, в то время как в данной работе она оценивается. Мы не рассматриваем эти возможности, предполагая норму инвестирования s постоянной (оценивается по данным, см. далее).

Поскольку целью работы является построение модели экономического роста России, экспоненциальная динамика объема использованной рабочей силы $\mathrm{L}_{\mathrm{t}}=\mathrm{L}_{0} \mathrm{r}^{\mathrm{t}}$ не адекватна. Вместо неё мы используем модель динамики БевертонаХолта [12], см. далее.

Оценка макроэкономической производственной функции для России имеет степень однородности, близкую к 2 (см. далее).

Исходные данные и использованные показатели

В качестве источника исходных данных использована мировая таблица Пенн (Penn World Table), версия 9.1 [13]. Диапазон использованных данных (с годовой периодичностью) был ограничен 2000-2017 гг. (последним, имеющимся в таблице). Были использованы следующие шесть показателей:

- rgdpna - реальный ВВП России, трлн. долл. США 2011 г.;

- етр - число занятых, млн. человек;

- avh - среднее число часов, отработанных одним занятым за год;

- hc - индекс человеческого капитала;

- rnna - реальный капитал, трлн. долл. США 
2011 г.;

- rkna - индекс услуг капитала, в постоянных национальных ценах 2011 г.

На их основе были сформированы следующие модельные показатели:

- реальный ВВП, трлн. долл. США 2011 г.: $\mathrm{Y}=$ rgdpna/1e6;

- объём труда с учётом человеческого капитала, млн. человеко-часов: $\mathrm{L}=\mathrm{emp}$ *avh*hc;

- реальный запас капитала, трлн. долл. США 2011 г.: K=rnna/1e6;

- индекс услуг капитала, 2011 г. = 1: KS=rkna.

Методика исчисления индекса человеческого капитала $\mathrm{KS}_{\mathrm{t}}$ в мировой таблице Пенн описана в [11] и основана на [8].

\section{Построение модели}

Модель (без учёта взаимосвязей между случайными возмущениями) представляет собой рекурсивных систему из четырёх уравнений, поэтому последние допустимо оценивать по-отдельности, что и было сделано. Оценки всех уравнений модели выполнены в пакете gretl [10]. Все коэффициенты уравнений статистически значимы на уровне $5 \%$.

1) Динамика объема использованного труда $\mathrm{L}_{\mathrm{t}}$. Обозначим $\mathrm{t}_{0}=\mathrm{t}-2000(\mathrm{t}-$ время в годах). Мы предполагаем, что динамика $\mathrm{L}_{\mathrm{t}}$ подчиняется модели Бевертона-Холта [12]:

$$
\mathrm{L}_{\mathrm{t}+1}=\frac{\mathrm{n}_{1} \mathrm{~L}_{\infty} \mathrm{L}_{\mathrm{t}}}{\mathrm{L}_{\infty}+\left(\mathrm{n}_{1}-1\right) \mathrm{L}_{\mathrm{t}}}
$$

Эта модель имеет явное решение [12], параметры которого и были оценены:

$$
\begin{aligned}
& \mathrm{L}_{\mathrm{t}}=\frac{\mathrm{L}_{\infty} \mathrm{L}_{0}}{\mathrm{~L}_{0}+\left(\mathrm{L}_{\infty}-\mathrm{L}_{0}\right) \mathrm{n}_{1}^{-\mathrm{t}} 0}+\varepsilon_{\mathrm{t}} \\
& \hat{\mathrm{L}}_{0}=404300 \pm 2600 \\
& \hat{\mathrm{L}}_{\infty}=486000 \pm 16000 \\
& \hat{\mathrm{n}}_{1}=1,079 \pm 0,025
\end{aligned}
$$

(здесь и далее после символа «п» приведены стандартные ошибки). Средняя ошибка аппроксимации $\mathrm{L}_{\mathrm{t}}$ составляет $0,63 \%$.

2) Неоклассическая производственная функция (оценена в логарифмической форме, MA(1) случайные возмущения):

$$
\begin{aligned}
& Y_{t}=e^{\beta_{0}+\beta_{1} t_{0}} \times\left(K_{t}\right)^{\beta_{2}} \times L_{t}^{\beta_{3}} \times e^{\varepsilon_{t}}+\theta \varepsilon_{t-1} \\
& \hat{\beta}_{0}=-17,244 \pm 0,016 ; \hat{\theta}=0,59 \pm 0,21 ; \\
& \hat{\beta}_{1}=0,0091 \pm 0,001 \& \\
& \hat{\beta}_{2}=0,414 \pm 0,046 ; \hat{\beta}_{3}=1,4157 \pm 0,0012
\end{aligned}
$$

Средняя ошибка аппроксимации $\mathrm{Y}_{\mathrm{t}}$ составляет $1,7 \%$.

3) Зависимость капитальных услуг от прироста капитала. Как было упомянуто выше, в производственную функцию следует включить услуги капитала $\mathrm{KS}_{\mathrm{t}}$, в то время как основное уравнение (см. ниже) входит запас капитала $\mathrm{K}_{\mathrm{t}}$. Для «замыкания» модели было обнаружено, что $\mathrm{KS}_{\mathrm{t}}$ достаточно точно воспроизводится с помощью логистической функции от (логарифмического) прироста $\mathrm{K}_{\mathrm{t}}$ :

$$
\begin{aligned}
& \mathrm{KS}_{\mathrm{t}}=\frac{\beta_{0}}{1+\exp \left(-\left(\beta_{1}+\beta_{2} \ln \left(\frac{\mathrm{K}_{\mathrm{t}}}{\mathrm{K}_{\mathrm{t}-1}}\right)\right)\right)^{+\varepsilon_{\mathrm{t}}}} \\
& \hat{\beta}_{0}=1,06 \pm 0,062 ; \hat{\beta}_{1}=1,36 \pm 0,38 ; \hat{\beta}_{2}=159 \pm 39
\end{aligned}
$$

Средняя ошибка аппроксимации составляет $3,75 \%$.

4) Динамика запаса капитала (модель линейной регрессии с $\mathrm{AR}(1)$ возмущением)

$$
\begin{aligned}
\mathrm{K}_{\mathrm{t}+1} & =\mathrm{s} \mathrm{Y}_{\mathrm{t}}+(1-\delta) \mathrm{K}_{\mathrm{t}}+\mathrm{U}_{\mathrm{t}+1}, \\
\mathrm{U}_{\mathrm{t}+1} & =\rho \mathrm{U}_{\mathrm{t}}+\varepsilon_{\mathrm{t}+1} \\
\hat{\rho}=0,54 & \pm 0,2 ; \hat{\mathrm{s}}=0,113 \pm 0,025 ; 1-\{\hat{\delta}=0,9749 \pm 0,006
\end{aligned}
$$

Средняя ошибка аппроксимации $\mathrm{K}_{\mathrm{t}}$ составляет 0,19\%. Прогноз (точечный) по построенной модели выполняется в следующем порядке: все значения $\mathrm{L}_{\mathrm{t}}$; далее последовательно $\hat{\mathrm{K}}_{\mathrm{t}+1}, \mathrm{KS}^{\wedge}{ }_{\mathrm{t}+1}, \hat{\mathrm{Y}}_{\mathrm{t}+1}$ и т.д. Рис. 1 иллюстрирует прогнозные значения темпа прироста ВВП России около $1,3 \%$.

\section{Выводы}

Проведённое моделирование позволяет сделать следующие заключения:

- на основании данных до 2017 г. включительно можно было спрогнозировать выход экономики России на темп роста реального ВВП около $1,3 \%$ в год, что подтверждается результатами 2018 г., в котором он составил около 1,5\%;

- вопреки распространённому мнению, труд в России очень высокопроизводителен: коэффициент эластичности реального валового выпуска экономики по труду составляет 1,42 , при этом наблюдается «синергетический» эффект, т.е. с ростом объема использованного труда на $1 \%$ реальный ВВП возрастает на $1,42 \%$;

- добиться реального ускорения развития 


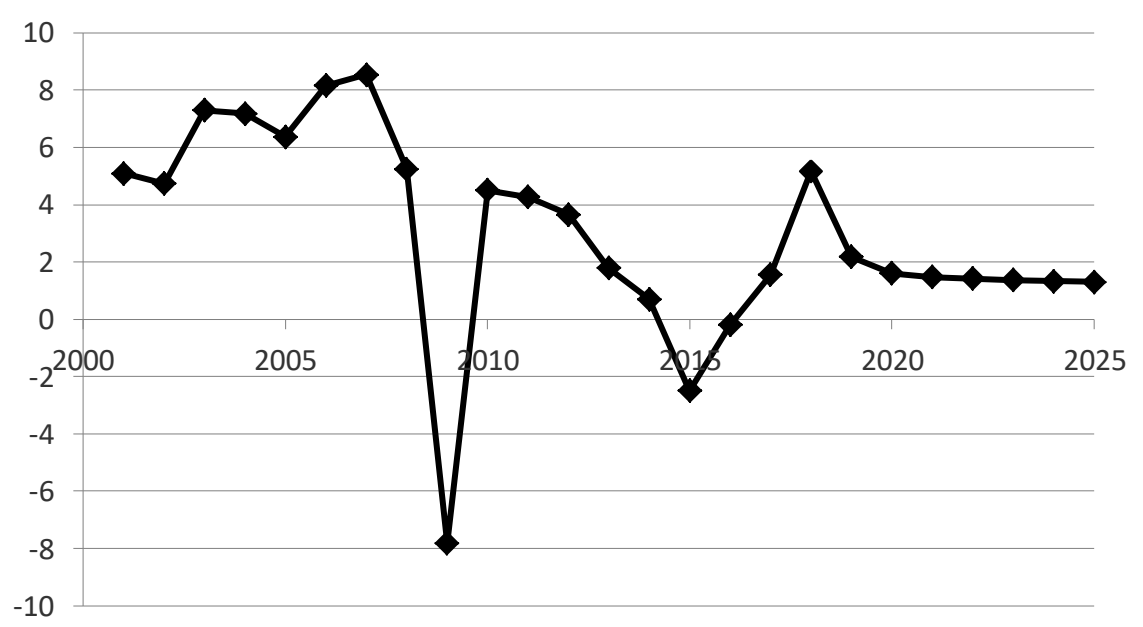

Puc. 1. Темпы прироста реального ВВП России,\% (2018-2025 гг. прогноз по модели).

экономики возможно лишь при увеличении в составе капитала «быстрых» его элементов - технологий, передового оборудования, программного обеспечения и т.п.; на уровне государственного управления этого можно добиться за счёт уменьшения объёмов финансирования инфраструктурных проектов; этот вывод может показаться парадоксальным, принимая во внимание большое значение, уделяемое Правительством РФ строительству инфраструктурных проектов; тем не менее, по нашему мнению, время, когда последние играли роль «драйверов» развития экономики, безвозвратно ушло; в условиях постиндустриальной и, тем более, цифровой экономики значение массовой перевозки грузов и пассажиров снижается - их, во многом, должны заменить передача ценных данных и общение с использованием телекоммуникационных сетей; завышенная роль инфраструктурных проектов, по нашему мнению, связана с относительной простотой их управления государственными структурами, наглядностью их результата и общеизвестным субъективным фактором;
- средняя норма инвестирования в 20002017 гг. составила 11,3\%;

- средняя годовая норма амортизации капитала в 2000-2017 гг. составила 2,51\%;

- важнейшим фактором роста экономики России выступает рост человеческого капитала; альтернативы ему нет.

Повышение пенсионного возраста приведёт к постепенному увеличению числа занятых и предельного значения последнего, однако этот эффект, как и эффект от повышения ставки НДС на экономический рост России, можно будет проследить позднее.

В целом, по нашему мнению, модифицированная модель Солоу-Свана с дискретным временем, дополненная феноменологической зависимостью услуг капитала от темпа прироста запаса капитала, моделью Бевертона-Холта для динамики использованного труда и отброшенным ограничением на линейную однородность макроэкономической производственной функции, даёт достаточно точное описание данных, и позволяет сделать осмысленные выводы и реалистичные прогнозы.

\section{Библиографический список}

1. Клепфиш Б.Р. Чувствительность макроэкономической модели Солоу-Свана // Перспективы развития мировой социально-экономической системы: сб. докл. междунар. науч.-практ. конф.- Саратов. - 2018.- С. 97100.

2. Коршунов В.А., Райнхардт Р.О. Оценка остатка Солоу для реального и потенциального ВВП: практический расчет для стран - членов ОЭСР // Вестник Института экономики РАН. - 2017. - № 3. - С. 137-149.

3. Мамонов М.Е., Пестова А.А., Сабельникова Е.М., Апокин А.Ю. Подходы к оценке факторов производства и технологического развития национальных экономик: обзор мировой практики // Проблемы прогнозирования. - 2015. № 6 (153).- С. 45-57. 
4. Масленников О.В. Классификация методов расчета совокупной факторной производительности // Вестник Воронежского гос. ун-та. Серия: Экономика и управление. - 2015. - № 4.- С. 172-175.

5. Петрова В.О., Кокоткина Т.Н., Садовин Н.С. Об оценке вклада факторов производства в экономический рост региона // Инновационные кластеры в цифровой экономике: теория и практика (ИНПРОМ-2017): сб. тр. науч.-практ. конф.- СПб.-2017.- С. 302-306.

6. Сериков П.Ю., Бучнев А.О. Предпосылки формирования и характеристика совокупной многофакторной производительности как инструмента оценки эффективности ресурсоограниченных экономических систем // Наука и технологии трубопроводного транспорта нефти и нефтепродуктов. - 2018. - Т. 8. - № 3.C. 338-351.

7. Acemoglu D. Introduction to Modern Economic Growth. - Princeton University Press. - 2009. - 1009 p.

8. Barro, R. J., Lee J.-W. A new data set of educational attainment in the world, 1950-2010// Journal of Development Economics. - 2013. - № 104.- P. 184-198.

9. Capital Services in PWT 9.1 / [Электронный ресурс].- Режим доступа: URL https://www.rug.nl/ggdc/docs/ pwt91_capitalservices_ipmrevision.pdf (дата обращения: 30.06.2019).

10. Gnu Regression, Econometrics and Time-series Library / [Электронный ресурс].- Режим доступа: URL http://gretl.sourceforge.net/ (дата обращения: 30.06.2019).

11. Human capital in PWT 9.0 / [Электронный ресурс]. - Режим доступа: URL https://www.rug.nl/ggdc/productivity/ pwt/pwt-documentation (дата обращения: 30.06.2019).

12. Pribylová $L$. The Solow-Swan model generalization with non-constant labor growth rate // Bulletin of the Czech Econometric Society. - 2011.- Vol. 18. - № 28. - 13 p. / [Электронный ресурс]. - Режим доступа: URL https://econpapers.repec.org/article/czxjournl/v_3a18_3ay_3a2011_3ai_3a28_3aid_3a182.htm (дата обращения: 30.06.2019).

13. The Database Penn World Table version 9.1 / [Электронный ресурс].- Режим доступа: URL https://www.rug.nl/ ggdc/productivity/pwt/ (дата обращения: 30.06.2019). 